\title{
Ghost Surgeries Must Be Eradicated
}

\author{
Young Dae Kweon
}

Korean Association of Plastic surgeons Public Information \& Public Affairs Committee Chairman Former Korean Society of Plastic and Reconstructive Surgeons Ethics Committee Chairman

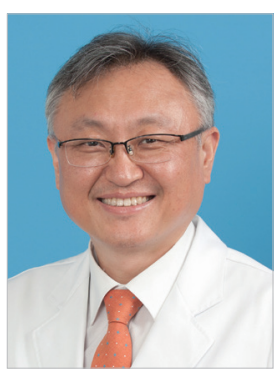

A medical institution possesses both public and private interests. However, recently, the public side of things has been emphasized because medical practice can involve invading the human body for treatment. As a result of this emphasis on public interests, medical law stipulates symbolic regulations on a hospital's duty to prevent infections and the duty of medical personnel to provide the best medical service, plus regulations on specific duties [1]. Fundamentally, the principle of respect for autonomy is an ethical demand for respecting others' autonomy [2]. Arbitrary medical treatment means the absence of valid consent from a patient because the doctor failed to adequately explain the disease at hand or the method of the medical treatment, or when a doctor carries out treatment even though the patient explicitly refused [3].

The Korean Assocication of Plastic Surgeons (KAPS) became aware of many illegal activities at G Plastic Surgical Clinic while investigating a case in which a high school student died of cerebral hypoxia during surgery induced by general anesthesia. KAPS found that a number of ghost surgeries had been performed at G Plastic Surgical Clinic for a long period of time, both systematically and recklessly (ghost surgeries involve one surgeon replacing another without the patient's consent) [4]. KAPS is actively researching U.S. legal precedents to push for judicial action and fine the doctors for causing bodily injury. This is to prevent unfair harm to patients who have lost their autonomy and right of choice and also to restore the fundamental trust between doctors and patients that has broken down.

In the past, there was no criminal penalty if a doctor substituted for another without the patient's consent. There is greater awareness of ghost surgery among legal circles today because of KAPS statements and debates on the subject after charges were filed with legal authorities. Because the purpose of medical practice is treatment, not injury, it does not meet the requirements of an assault causing bodily injury. Moreover, proving intentionality is difficult because the doctor must not only recognize the bodily injury inflicted on the patient, but also intend for the injury to occur. To justify medical practice, the work itself must be justifiable. KAPS is thinking over whether arbitrary medical treatment could also be considered justifiable. Intentionality could be found in cases in which a different doctor performs surgery in place of the doctor whom the patient gave consent to. The definition of an assault is wielding influence on the body. Ghost surgery should be deemed an intentional violation of the body, not an accident. An assault causing bodily injury considers the act of invading the body. Since a surgical procedure is considered an act of invasion, it meets the requirement for an assault causing bodily injury [4]. Professional negligence means calculating the liabilities of actions that have already occurred. Even though the subject of discussion is entirely different, in past judicial precedent, Korean courts have routinely misunderstood and expected an explanation of the connection between the two.

There can be circumstances precluding wrongfulness for the assault causing bodily injury when there is patient consent on the basis of sufficient explanation. From now on, the contents of the cursory surgery consent form must become more specific and clear for the patient's right to know and right to choose. In addition, ghost surgery may qualify as fraud. If one deceives an- 
other, commits an act of disposal based on that deception, profits from the action, etc. the case can qualify as fraud. Not informing the patient of a change in doctors is an act of deception.

While KAPS believes ghost surgery should be punishable by law as a fraud case [5], if we consider victims suffering from "serious hazard" were primarily deprived of their right over their own body and their right to life, we believe ghost surgery should be punishable as an assault causing bodily injury or an assault causing grievous bodily injury. The right for a doctor to use medical instruments to perform a surgical procedure on a patient's body is only granted by the permission and consent of the patient-it is not an innate right that comes with a medical license. Therefore, ghost surgery is an assault instigated by someone with no right to do so, and cannot be seen as a justifiable surgical procedure [4]. In order to preserve their vested rights, some doctors cite the practices in training hospitals to oppose the validity of assault charges [4]. However, even training hospitals respect the patient's right to know by stating the name of the assistant surgeon under training [4]. In this case, there is no legal problem if the promised doctor performs surgery together with the assistant. Looking at U.S. legal precedent, ghost surgeries have been punished when the promised doctor was not even present in the operating room, and the surgery was performed by a doctor that the patient did not approve, or by an assistant. Patients usually discovered the switch in doctors when undergoing treatment for complications or side effects, and then pressed charges.
Ghost surgery is a crime against the public. KAPS promises to impose strict sanctions against all criminal activities inside the operating room, in order to restore the trust toward doctors. Plastic surgeons must not intentionally assign their surgical procedures to other doctors so that they can maintain their patients' trust. They must faithfully perform surgery for their patients.

\section{REFERENCES}

1. Korean Medical Association. Manual for medical law [uilyobeobhaeseoljib]. Seoul: Korean Medical Association; 2004.

2. Gillon R. Philosophical medical ethics. Chichester: Wiley; 1986.

3. Medicaltimes [Internet]. Seoul: Medicaltimes; 2015 [cited 2016 Jul 7]. Available from: http://www.medicaltimes.com/ Users4/News/newsView.html?ID=1098327.

4. Perna v. Pirozzi, 457 A. $2 d 431$ (N.J. Supreme Court, 1983). 5. Meyers v. Epstein, 232 F. Supp. 2d 192 (N.Y., 2002).

Correspondence: Young Dae Kweon

GangNam Aesthetic Plastic Surgical Clinic, Hyemin Tower 6F 209, Osan-ro, Osan 18137, Korea Tel: +82-31-377-7575, Fax: +82-31-377-7576, E-mail: psdrowl@ hanmail.net

No potential conflict of interest relevant to this article was reported.

Received: 6 Jul 2016 • Revised: 8 Jul 2016• Accepted: 9 Jul 2016 pISSN: 2234-6163 • elSSN: 2234-6171

http://dx.doi.org/10.5999/aps.2016.43.4.309 • Arch Plast Surg 2016;43:309-310 